\title{
Obesity and nutrients and the interactions of environment factors, beside starvation in the world
}

\begin{abstract}
Basic nutrients are necessary for surviving and healthy life for human. Some of them essential food compounds, On the other hand, Nutrition is large and detail term for to be able to explain its meaning because of the main factors; environment, ecology, tradition, economy, education, health events, age steps, special terms of life, gender, life style, exercise, pregnancy or lactation periods for women etc. All of these factors should interact for each other's. The environment factors include ecology, climate, geography and tradition for nutrition habits. A typical example is Mediterranean type nutrition or far east nutrition habits.
\end{abstract}

Volume 7 Issue I - 2017

Necla Çağlarırmak

Food Process Department, Manisa Celal Bayar University, Turkey

Correspondence: Necla Çağlarırmak, Food Process Department, Manisa Celal Bayar University, Saruhanli College, Saruhanli-Manisa,Turkey, Email neclacaglarirmak@gmail.com

Received: May 28, 2017 | Published: July |I, 2017

Keywords: nutrients, food chemistry, environment, nutrition habits, exercise

\section{Introduction}

The basic terms and science of health or life sciences related to obesity places in main nutrients of food chemistry. The main macronutrients are lipids, carbohydrates, protein, micronutrients are vitamins and nutritive minerals. Essential food components are essential fatty acids, essential amino acids, vitamins and minerals. Balanced and sufficient diet comprises essential nutrients and enough calorie intakes. What is the most effective factors for nutrition? It should be mental management probably and other factors that are determined according to conditions of individuals and environment. The obesity studies are making until long time e.g. it was established that the prevalence rates for overweight and obese people were different in each region, with the Middle East, Central and Eastern Europe, and North America having higher prevalence rates. ${ }^{1,2}$

Overweight is a always important health problems leading to various diseases. ${ }^{3}$ Food safety and water safety are the vital importance for health and preventing disease too. Clean and drinking water is the great requirement for human and all of the livings. It must be known that water sources are very limited for all over the World especially due to global warming and fast population increase of some regions of the world. Sufficient water and food are essential requirements for surviving beside a little rich class of societies those are outside of this article.

Obesity should be one the biggest of our life problems because of degrees of development levels of societies. It was reported that the prevalence of overweight and obesity has increased across the world from approximately $29 \%$ of adults to $38 \%$ from 1980 and $2013 .{ }^{4}$ The development of industry and life conditions, loosing tradition of nutrition habits, consuming ready foods due to food tradition of societies are estimated that occurring obesity problem. Of course, there are lots of factors which contribute to obesity. What can we do overwhelming the obesity problem over the world beside famine and starvation is a great problem for countries? First of all, environment factors must be detected well even including environment pollution. Food safety and environment factors with energy types are related each others including nutrition. Food safety should stay in the mind every life conditions. ${ }^{5}$ In this review, these topics were summarized as key and main ideas.
If food chemistry and molecular biology are known well, there should be solved an important section of excessive nutrition causing obesity with other affected factors.

\section{Food and nutrition pyramids}

Every time nutrient intake must be taken according to food biochemistry and nutrition principles such as food pyramids even they can change in the kinds of periods but basically principles are the same. Food pyramid can be affected ecology, agriculture and food supply opportunity, economy, education levels, traditions and environment of societies (Figure 1).

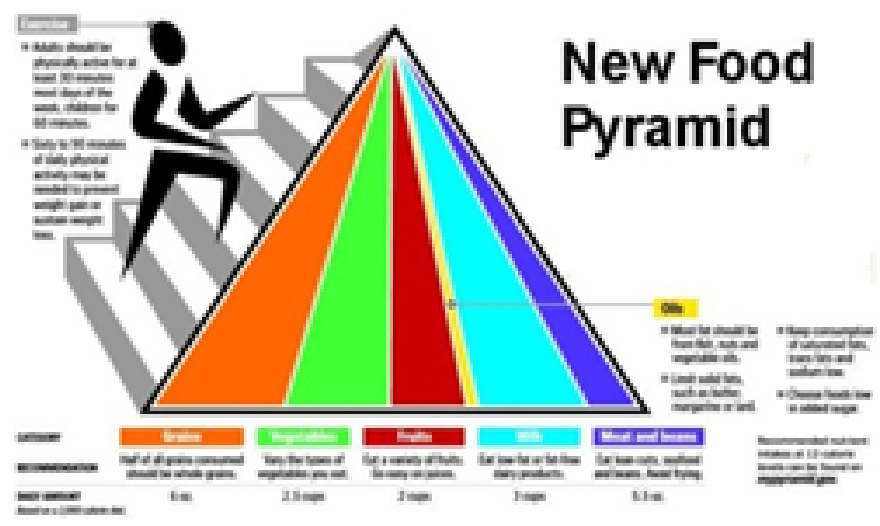

Figure I Presentation of new food pyramid. ${ }^{23}$

\section{Lipids}

Lipids are so large group contain kinds of food groups. The edible fats and oils should be in large group and the most interested compounds of lipids. The fats and oil consist of glycerol and fatty acids that separated as saturated an unsaturated fatty acids. ${ }^{6}$ In cardiovascular diseases fatty acids play significant role in the body. The fats and oil gives highest calory tor body as $1 \mathrm{~g}$ fat gives $9 \mathrm{kcal}$. High calory intake cause to getting weight and also cause to cardiovascular diseases especially containing saturated fatty acid diets (Figure 2).

In cardiovascular health, Polyunsaturated fatty (PUFAs) acids have 
beneficial effects. In the literature, proved to functional properties and health benefits of unsaturated fatty acids. $1 \mathrm{~g}$ of fish oil has shown to reduce overall and cardiovascular mortality, myocardial infarction, and sudden cardiac death. ${ }^{7}$

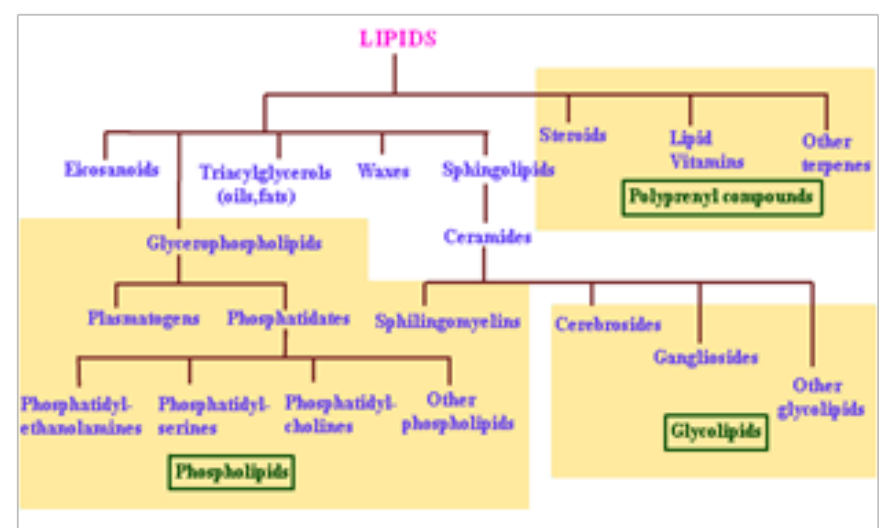

Figure 2 Lipid groups. ${ }^{22}$

On the other hand fats provides high energy intake, provides $\% 25-$ 30 of total calories daily. The fast foods nutrition habits, some fried foods such as potatoes or similar foods provides high energy intake and one of the important factors contributing the obesity with kinds of health problems.

\section{Proteins}

"Protos" derived from Greek word means primary and first, essential for life, it is the vital nutrient and vital for balanced diet and important food factor for human. Especially, plant originated protein consumption with animal originated protein sources can be prevent obesity with other preventing factors such as exercise. Protein consists of amino acids which are derived from essential amino acids that must be taken from foods because of informed by the body and other group. ${ }^{8}$ These components can be synthesized by the body. There are 20 or 23 amino acids which are bound with peptide bounds each other's (Table 1).

Table I Amino acid groups. ${ }^{20}$

\begin{tabular}{ll}
\hline Essential amino acids & Nonessential amino acids \\
\hline Arginine & Alanine \\
Histidine & Asparagine \\
Isoleucine & Aspartic acid \\
Leucine & Citrulline \\
Lysine & Cysteine \\
Methionine & Glutamic acid \\
Phenylalanine & Glycine \\
Threoniwne & Hydroxyglutamic acid \\
Tryptophan & Norleucine \\
Valine & Proline \\
& Serine \\
\hline
\end{tabular}

Proteins have basic functions in the body in growing, development, curing after diseases, forming anticors, Proteins play an important part in the creation of every new cell and every new individual. $1 \mathrm{~g}$ protein gives $4 \mathrm{kcal}$, proteins should be used for their vital roles in the organism. The basic compound of proteins are amino acids those have peptide bounds as forming macromolecules of kinds of proteins, namely the amino acids in a polypeptide chain are linked by peptide bonds. Once linked in the protein chain (Figure $3 \& 4$ ).

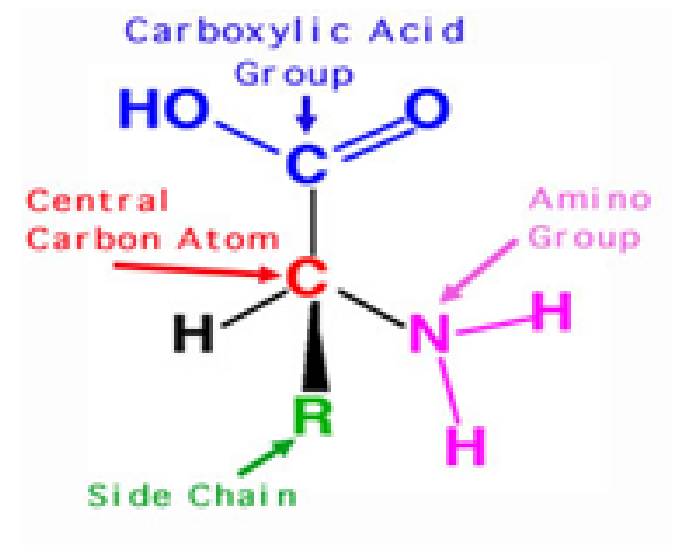

Figure 3 The Amino structure.

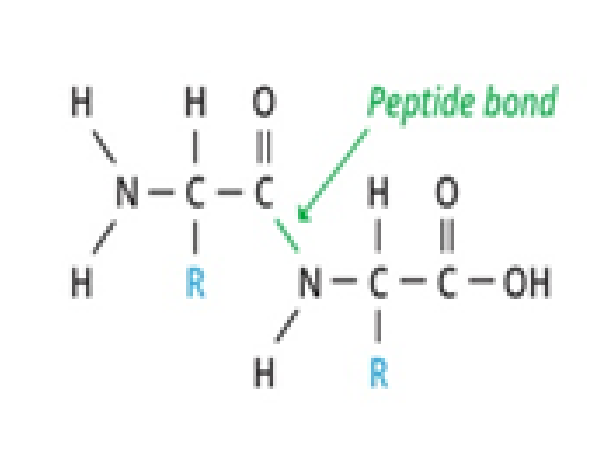

Figure 4 Peptide bound presentation. ${ }^{24}$

\section{Carbohydrates}

Carbohydrates are the most debated substances for obesity, diabet types, or any related diseases. On the other hand, it is common reality must be staffing items for human for everywhere, the highest interest for the preventing famine and starvation must be harvesting of cereals with other food sources. The basic compound of carbohydrates is monosaccharide (Figure $5 \& 6$ ).

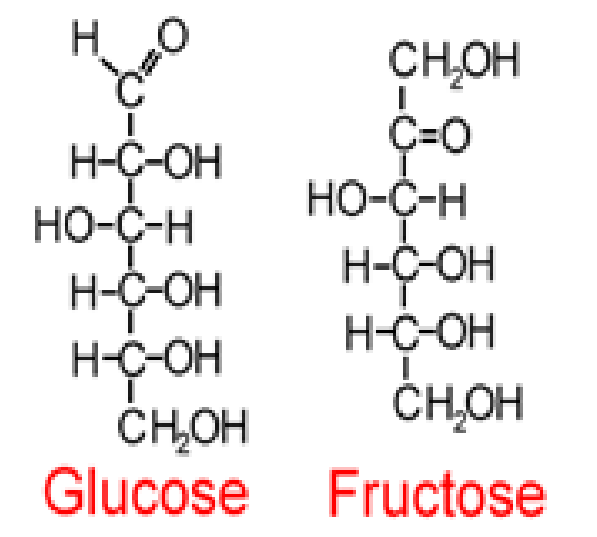

Figure 5 Examples of monosaccharide structure as Fischer formula, The general formula is $\mathrm{C}_{n}\left(\mathrm{H}_{2} \mathrm{O}\right)_{n}$ or $\mathrm{C}_{n} \mathrm{H}_{2 n} \mathrm{O}_{n}$. 


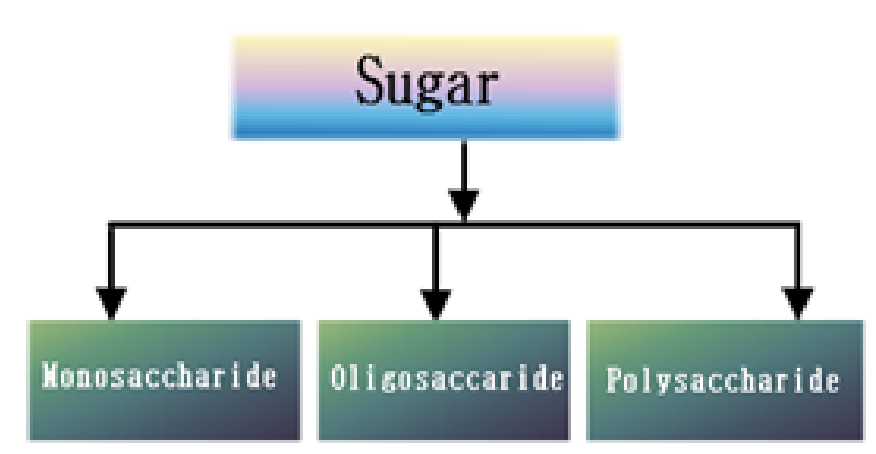

Figure 6 Chemical classification of carbohydrates. ${ }^{18}$

Carbohydrates can provide $50-60 \%$ energy intakes daily besides debating consumption of carbohydrates. In getting weight the high calory intake is not a single factor, spending energy by exercise is a indicating factor with other factors such as environment factor, genetic factors etc. One gram of carbohydrates equals about 4 calories, Sugars and starches are broken down by the body into glucose (blood sugar) to be used as energy. Carbohydrates have important role for mental health. Fibers affected cholesterol mechanism positively, and they regulate the intestine movement and functions then prevent colon cancer. Carbohydrate consumption varies for every individual due to kinds of factors. The Glycemic Index (GI) is a relative ranking of carbohydrate in foods according to how they affect blood glucose levels. ${ }^{9}$

There are two types of glisemic index high glycemic index (GI) carbohydrates enter the bloodstream as glucose rapidly, while low GI carbohydrates enter slowly because they take longer to digest and break down. Fibers and whole cereal sources classified in to low GI carbohydrates which have beneficial effects carbohydrates metabolism. Low GI carbohydrates have the following benefits: Low glycemic diets can be recommended that would be better for weight loss. A diet of foods less likely to spike blood sugar levels helps dieters lose more weight, better diabetes control, blood cholesterol levels will most likely remain healthy, heart disease risk is lower, control of appestat (Figure 7). ${ }^{10}$

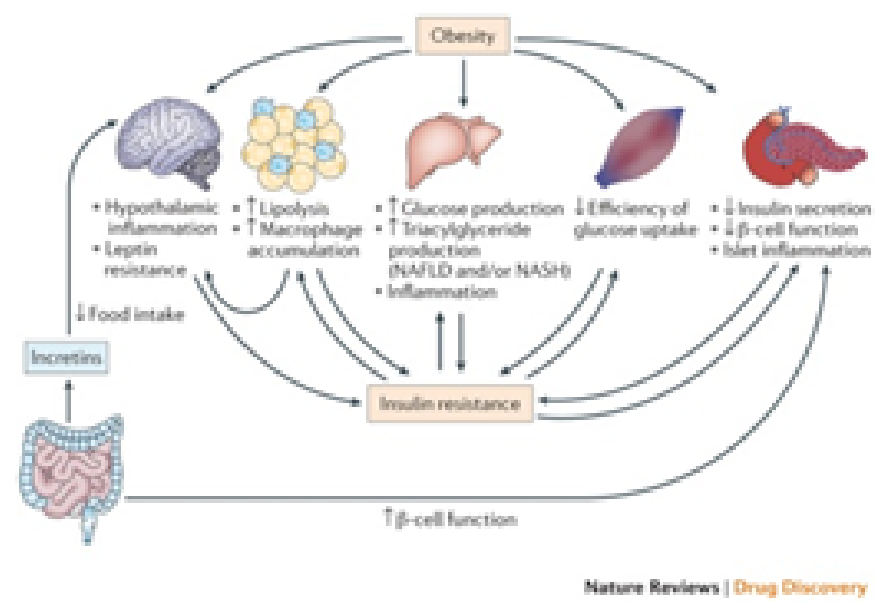

Figure 7 Pathway of obesity. ${ }^{25}$

If nutrition principles can be applied with interactions other factors such as exercise, and preference of traditional sorts of foods and nutrition habits, and returning natural life, will be help preventing of obesity apart from special events genetic, special diseases etc.

\section{Environmental factors}

Modern and city life, sedentary jobs, life habits watching TV in long time by taking high calory containing foods, fast consumption of fast foods and low income of people, (low budget of people opposite effects obesity and normal weight of people), under becoming under excessive stress and pressure in the life, increasing cost of basic nutrients such as protein originated foods, increasing prices of vegetables, legumes and fruits due to climate change affected by global warming with other factors which can varied according to countries conditions are effective development and increasing of obesity. Some of traditional nutrition such as Mediterranean type, Traditional Turkish foods including, whole cereals, legumes and vegetables with mixtures of meats with less fat addition and salt, Far East type even the most of countries traditional foods except containing of excessive amount carbohydrate, fat and oil and salt can be support healthy nutrition. Actually every originated fast foods those may be change for every nations can cause to obesity. Good and healthy nutrition can be provided above mentioned rules with education that begins from elementary school with exercise. The supporting date was present in the literature. ${ }^{11}$ The other reports were studied Muller et al., ${ }^{12}$ obesity prevention programmes are promising with education programs. The childhood obesity is a great interest for sustainable life and nutrition habits. ${ }^{13}$ Another data from literature was reported as complex relationship between environmental and individual determinants of obesity, which can play an important role in the development of effective interventions and expand obesity control programs in large cities. ${ }^{14}$

\section{Famine and starvation}

There are lots of people suffering from starvation who cannot get their foods and there are so tragic results such as death because starvation. ${ }^{15}$ The sources says that "The world is facing its largest humanitarian crisis since 1945, the United Nations says, issuing a plea for help to avoid "a catastrophe". UN news said that more than 20million people faced the threat of starvation and famine in Yemen, Somalia, South Sudan and Nigeria. (Figure 8). FAO explains hunger as being synonymous with chronic undernourishment. Fao.org. web pages.

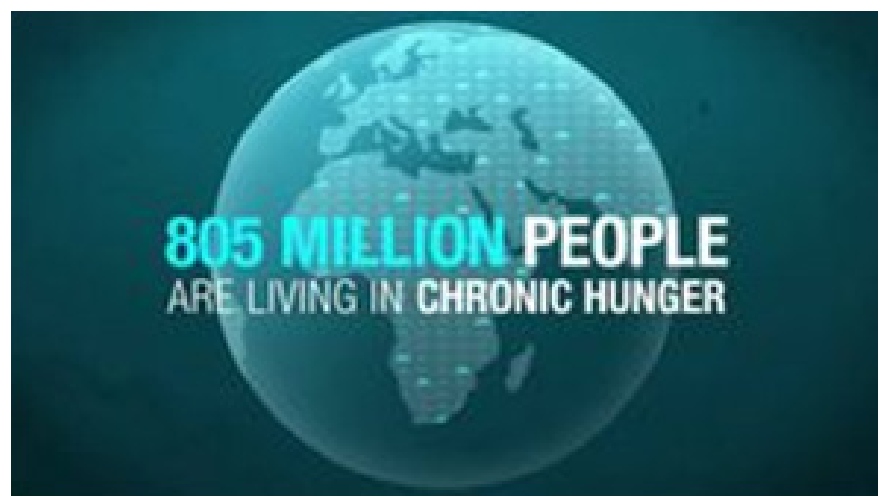

Figure 8 There are lots of people those suffering from hunger in the world beside obesity

a. The important portions of world people are into obesity index due to excessive consumption of foods also dispended in high quantities. FAO reported that roughly one third of the food produced in the world for human consumption every year approximately 1.3 billion tonnes - gets lost or wasted. 
b. Food losses and waste amounts to roughly US\$ 680billion in industrialized countries and US\$ 310billion in developing countries (Figure 9). ${ }^{16}$

c. Recent studies suggest the African nation of Burundi has the highest levels of hunger and undernourished people worldwide. More than 10years of war, along with poverty and overpopulation, have affected the nation's economic and nutritional conditions.

d. The UN World Food Program is hoping to help FAO reported as determinations for waste of foods: The food currently lost or wasted in Latin America could feed 300million people, ywasted in Europe could feed 200million people and food currently lost in Africa could feed 300million people. ${ }^{16-22}$

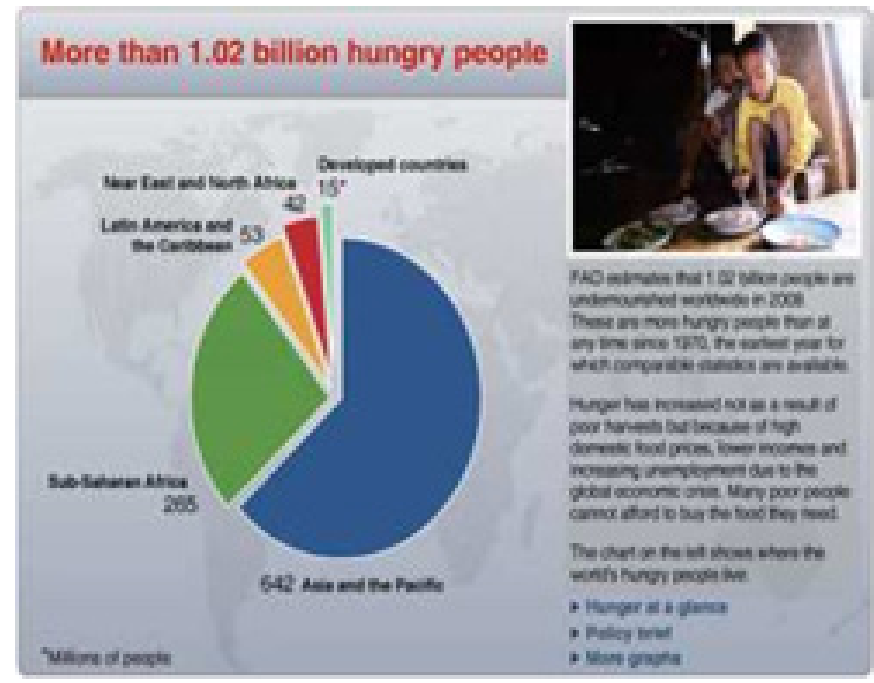

Figure 9 Ratio of Hungary people. ${ }^{17}$

\section{Conclusion}

In the review from base of nutriton and food chemistry with obesity introductions to waste of foods and starvation and affected factors; environment and rekated subjects, nutrition habits of socities and unbalanced disturbutions of food consumptions in the world was summarized with basic ideas. Everybody knows well there is a one "World for surviving " we must protect our planet. There should be relationship balanced diet, protection planet, sharing food sources equally, education all of the related subjects and overcoming the obesity and also starvation for sustainable environment and food supply.

\section{Acknowledgements}

None.

\section{Conflict of interest}

The author declares no conflict of interest.

\section{References}

1. James Philip T, Leach R, Kalamara E, et al. The worldwide obesity epidemic. Obes res. 2001;9(Suppl 4):228S-233S.

2. Swinburn B, Gill T, Kumanyika S. Obesity prevention: a proposed framework for translating evidence into action. Obes rev. 2005;6(1):2333

3. Aslan D, Atilla S. Önemli Bir Sağlık Sorunu: Şişmanlık. Sürekli Tıp Ĕgitim Dergisi (Sted). 2002;11(5):169-171.

4. Crino, Michelle, Vandevijvere S, et al. The influence on population weight gain and obesity of the macronutrient composition and energy density of the food supply. Curr Obes Rep. 2015;4(1):1-10.

5. Çağlarırmak N. An Aspect Of Food Safety, Environment Pollution And Agriculture Contamination With Supplying Energy Sources. Turkish Journal of Agricultural and Natural Sciences. 2016;1:1357-1363.

6. Demirci M. Gida Kimyası. Glda Teknolojisi Dergi Yayın. 2016:5-123.

7. Çağlarırmak N. A review:Nutrition, Food Safety, Process and Waste of Fish, Annals. Food Science and Technology. 2016;17(1):212-217.

8. Menzel PA. Nutrients in Food. In Mayo Clinic Proceedings. 2000;75(11):1225-1226

9. Glycemicindex.

10. Carbohydrates: What You Need To Know.

11. Hardus PM, van Vuuren CL. Public perceptions of the causes and prevention of obesity among primary school children. International journal of obesity. 2003;27(12):1465-1471.

12. Müller MJ, Mast M, Asbeck I, et al. Prevention of obesity-is it possible? Obes Rev. 2001;2(1):15-28.

13. Bailey Davis, Lisa. WIC Nutritionist Perspectives on Opportunities and Challenges Regarding Care Coordination with Primary Care Providers for Early Childhood Obesity Prevention. Journal of Patient-Centered Research and Reviews. 2016;3(3):219.

14. Matozinhos Fernanda Penido. Association between environmental factors and individual factors with obesity in Brazilian adults. European Journal of Public Health. 2015;25(suppl 3):175-249.

15. UN: World facing greatest humanitarian crisis since 1945 .

16. SAVE FOOD: Global Initiative on Food Loss and Waste Reduction.

17. World Hunger.

18. Carbohydrates.

19. Epithelial-mesenchymal transition: a new target in anticancer drug discovery.

20. Proteins.

21. Adult Male and Female Height to Weight Ratio Charts.

22. Lipids.

23. Old and New Food Pyramid with Pictures.

24. Peptide bound presentation.

25. Pathway of obesity. 